\title{
Designing laboratory metallic iron columns for better result comparability
}

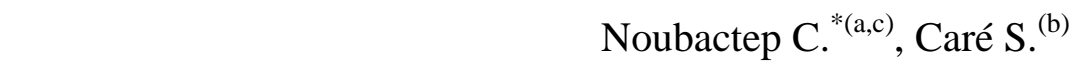

\section{Abstract}

Despite the amount of data available on investigating the process of aqueous contaminant removal by metallic iron $\left(\mathrm{Fe}^{0}\right)$, there is still a significant amount of uncertainty surrounding the design of $\mathrm{Fe}^{0}$ beds for laboratory testing to determine the suitability of $\mathrm{Fe}^{0}$ materials for field applications. Available data were obtained under various operating conditions (e.g. column characteristics, $\mathrm{Fe}^{0}$ characteristics, contaminant characteristics, oxygen availability, solution $\mathrm{pH}$ ) and are hardly comparable to each other. The volumetric expansive nature of iron corrosion has been univocally reported as major drawback for $\mathrm{Fe}^{0}$ beds. Mixing $\mathrm{Fe}^{0}$ with inert materials has been discussed as an efficient tool to improve sustainability of $\mathrm{Fe}^{0}$ beds. This paper discusses some problems associated with the design of $\mathrm{Fe}^{0}$ beds and proposes a general approach for the characterization of $\mathrm{Fe}^{0}$ beds. Each $\mathrm{Fe}^{0}$ column should be characterized by its initial porosity, the composition of the steady phase and the volumetric proportion of individual materials. Used materials should be characterized by their density, porosity, and particle size. This work has introduced simple and reliable mathematical equations for column design, which include the normalisation of raw experimental data prior to any data treatment.

Key words: Deep bed filtration, Operational parameters, Results comparability, Water Filtration; Zerovalent iron. 
27 Metallic iron $\left(\mathrm{Fe}^{0}\right)$ as reactive medium for aqueous contaminant removal has been intensively investigated during the last two decades [1-6]. These studies have demonstrated the potential of $\mathrm{Fe}^{0}$ for use in (i) subsurface permeable reactive barriers [1], (ii) above ground wastewater treatment [3,5], (iii) household water filters [7-10], and (iv) drinking water treatment plants [11-13]. The fundamental mechanisms of contaminant removal in $\mathrm{Fe}^{0}$ beds are adsorptive size-exclusion and co-precipitation [5,6,13-19].

Data for pilot- and full-scale remediation scheme are mostly obtained from laboratory columns [20-22]. Laboratory column studies are in turn conventionally designed based on batch treatability studies [21,23,24]. A major problem of available data from batch studies is the poor comparability of results from different laboratories using different conditions. Most experimental conditions are not relevant for field situations [25,26]. For example, only shaking intensity lower than $50 \mathrm{~m}^{-1}$ could enable the formation of a universal oxide-scale in the vicinity of the $\mathrm{Fe}^{0}$ surface as observed in column studies and in full-scale barriers [25]. A careful look behind published data on laboratory column experiments ([27-32]; see Tab. 1) also demonstrates large variability in the experimental design. General design procedures are not available. Differences in design procedures may cloud interpretations of reported data. Therefore, any effort to ensure the comparability of laboratory results over time and space would accelerate the development of the $\mathrm{Fe}^{0}$ remediation technology.

The objective of the present communication is to improve the comparability of laboratory column results by offering the scientific community tools for a common basis for the design of $\mathrm{Fe}^{0}$ beds. Previous theoretical works $[9,31,32]$ have demonstrated that mixing $\mathrm{Fe}^{0}$ and other materials (gravel, pumice, sand, quartz) is the prerequisite for long service life. This mixture should be characterized by the volumetric proportion of $\mathrm{Fe}^{0}$ (Fig. 1) and other materials (additives) and the initial porosity [32]. The specific objective of this communication is to 51 establish equations for the evaluation of the mass of the materials to be used. 
53 Cylindrical columns usually used for laboratory experiments primarily differ in their size 54 (diameter * length). For example, columns with $5 \mathrm{~cm}$ internal diameters exist with lengths varying from 30 to $100 \mathrm{~cm}$ (Tab. 1). Completely filling the six different columns from Tab. 1 with reactive materials (e.g. $\mathrm{Fe}^{0}$ ) will yield 0.2 to $9.8 \mathrm{~kg}$ of $\mathrm{Fe}^{0}$ for the experiment. The question is how to objectively compare results obtained with various amount of the same materials? The situation is exacerbated when the materials are different (particle size, shape, chemical composition or generally intrinsic reactivity). When material mixture should be performed, the rationale for purposeful mixing should be developed.

Using the material apparent specific weight tabulated by Noubactep and Caré [9], Tab. 1 clearly shows that a given volume (e.g. $\mathrm{V}_{\text {solid }}$ in the same column) is occupied by a mass $\mathrm{m}$ of pumice, $4.14^{*} \mathrm{~m}$ of sand, and $12.19 * \mathrm{~m}$ of $\mathrm{Fe}^{0}$. The coefficients are the ratios of the apparent specific weights $\left(\rho_{\mathrm{i}} / \rho_{\mathrm{j}}\right)$. This observation confirms that the volumetric ratio is the sole appropriate approach to design column studies. Accordingly, an approach to have comparable results could be to fix the $\mathrm{Fe}^{0}$ volume. A given $\mathrm{Fe}^{0}$ volume corresponds to various heights depending on the column internal diameter. Accordingly, beside used $\mathrm{Fe}^{0}$ mass (corresponding to a volumetric fraction of solid), the column dimensions should always be specified. Three examples are given below for illustration.

In the laboratory, the $\mathrm{Fe}^{0}$ amount is commonly given in weight ( $\mathrm{g}$ or $\mathrm{kg}$ ). Therefore, a practical approach is to fix a mass of $\mathrm{Fe}^{0}\left(\mathrm{~m}_{0}\right)$ which is likely to enable observable effects within a reasonable time (e.g. 6 weeks).

- An experiment is designed to compare the reactivity of different $\mathrm{Fe}^{0}$ materials. Parallel column experiments have to be conducted in which $\mathrm{Fe}^{0}$ is the sole variable and the same mass $\left(\mathrm{m}_{0}\right)$ is used in individual columns.

- An experiment is designed to compare the impacts of chloride $\left(\mathrm{Cl}^{-}\right)$and sulphates $\left(\mathrm{SO}_{4}{ }^{2-}\right)$ on the efficient of a $\mathrm{Fe}^{0}$ for methylene blue (MB) discoloration. The three following parallel 
experiments could be conducted with the mass $\mathrm{m}_{0}$ of a $\mathrm{Fe}^{0}$ sample: (i) MB in deionised water, (ii) $\mathrm{MB}$ in a $\mathrm{Cl}^{-}$solution, and (iii) $\mathrm{MB}$ in a $\mathrm{SO}_{4}{ }^{2-}$ solution. The $\mathrm{MB}$ concentration is the same in all experiments, $\mathrm{Cl}^{-}$and $\mathrm{SO}_{4}{ }^{2-}$ solutions have the same equivalent concentration.

- An experiment is designed to compare the impact of mixing $\mathrm{Fe}^{0}$ with additives. The reference system should be the mass $\mathrm{m}_{0}$ of $\mathrm{Fe}^{0}$, and volumetric proportions of $\mathrm{Fe}^{0}$ have to be replaced by appropriated additives. Tab. 1 shows that each column is characterized by a constant pore volume which is the external or inter-granular porosity. For porous materials the internal porosity or intra-granular porosity has been discussed as a storage room for in-situ generated corrosion products and thus a tool to sustain $\mathrm{Fe}^{0}$ reactivity $[9,10,32]$. Similarly, mixing $\mathrm{Fe}^{0}$ and non-porous inert additives is beneficial for the system because inert material will not contribute to pore filling or filter clogging.

The next section will establish some general equations to support design operations.

\section{$3 \quad$ Mathematical equations for column design}

A hypothetical cylindrical filter having an inner diameter $\mathrm{D}$, a length $\mathrm{L}$, and a reactive zone $h_{r z}$ is considered. The reactive zone is the fraction of $L\left(L>h_{r z}\right)$ containing the reactive material, possibly mixed with selected additives. The filter is filled by spherical particles (reactive materials and non-reactive additives) having a constant diameter $\mathrm{d}$. Considering the granular material as composed of mono-dispersed spheres subjected to soft vibrations, the column compactness (or packing density) C ranges between 0.60 and 0.64 for a random close packing but it is generally considered to be equal to 0.64 (limit value). It can be noticed that the value of the compactness depends on various parameters as the distribution size of particles, their shape [33-34]. The theoretical value of $C=0.64$ is strictly valid for particles with spherical shape and similar sizes. It is assumed in this study that ratio of cylinder diameter $(\mathrm{D}=2 * \mathrm{R})$ to particle diameter $(\mathrm{d}), \beta=2 * \mathrm{R} / \mathrm{d}$ is optimal for axial hydrodynamic dispersion [36,37]. 
103 The volume of the reactive zone $\left(\mathrm{V}_{\mathrm{rz}}\right)$, the volume of solid $\left(\mathrm{V}_{\text {solid }}\right)$, the volume of inter104 granular pores $\left(\mathrm{V}_{\text {pore }}\right)$, the volume of individual solids $\left(\mathrm{V}_{\mathrm{i}}\right)$ with the apparent specific weight $105 \rho_{\mathrm{i}}$, and the thickness of the reactive zone $\left(\mathrm{h}_{\mathrm{rz}}\right)$ are given by Eq. 1 through Eq. 6:

or

$$
\alpha_{\text {pore }}+\alpha_{1}+\alpha_{2}+\alpha_{3}+\alpha_{4}=1
$$$$
\alpha_{1}+\alpha_{2}+\alpha_{3}+\alpha_{4}=1-\alpha_{\text {pore }}=C
$$

124 Eq. 8 is very important for the calculations of the amounts of individual additives to achieve

125 wished material mixtures as will be discussed in the next section. Eq. 8b suggests that $\alpha_{i}$ is

For instance, for a system containing a mixture of four solid phases, Eq. 7 should read:

$$
\text { necessarily a fraction of C. Thus, a simple rule of proportion can be established to calculate } \alpha_{i}
$$


127 for each proportion $\mathrm{P}_{\mathrm{i}}$ of the solid phase. C necessarily corresponds to $100 \%$ solid. The

128 relation between $\alpha_{i}$ and $P_{i}$ is given by Eq. 9:

129

$$
\alpha_{\mathrm{i}}=\mathrm{C}^{*} \mathrm{P}_{\mathrm{i}} / 100
$$

130

131

132

133

134

135

136

137

138

139

140

141

142

143

144

145

146

147

148

149

150

151

Tab. 2 gives some values of $\alpha_{i}$ for selected relevant $P_{i}$ values. For example, if a quaternary system should be made up of $40 \%$ of material A, $30 \%$ material B, $20 \%$ material C and $10 \%$ material D, the coefficients to be used are: $0.256,0.192,0.128$ and 0.064 respectively. A quaternary system seems to be strange or complicated. However, such a system could comprise $\mathrm{Fe}^{0}$ as basic reactive material, $\mathrm{MnO}_{2}$ to sustain $\mathrm{Fe}^{0}$ reactivity, pumice as storage solid and quartz as non-porous inert filling material.

\subsection{Initial porosity of reactive the zone}

In the case of non porous spherical particles, the initial porosity of the reactive zone $\Phi_{0}$ is the inter-granular porosity $\alpha_{\text {pore }}$ and is given by Eq. 10 [32].

$$
\Phi_{0}=1-\mathrm{C}
$$

If individual particles are porous, the intra-granular porosity should be considered [32]. In this case the initial porosity should read:

$$
\Phi_{0}=(1-\mathrm{C})+\sum \alpha_{\mathrm{i}} \phi_{\mathrm{i}}
$$

where $\mathrm{C}$ is the compactness of the reactive zone, $\alpha_{i}$ the volumetric fraction of the solid $\mathrm{i}$ (Tab.

2) and $\phi_{\mathrm{i}}$ its internal porosity.

Equations 1 to 11 are the basis for purposeful experimental design as will be discussed below for selected cases.

\section{$4 \quad$ Designing some $\mathrm{Fe}^{0}$ systems}

\subsection{A four component system}

For the design of a quaternary system of $\mathrm{Fe}^{0}$, sand, pumice and $\mathrm{MnO}_{2}$, Eq. 8 can be used:

$$
\begin{aligned}
& \mathrm{V}_{\mathrm{rz}}=\mathrm{V}_{\mathrm{rz}}\left(\alpha_{\text {pore }}+\alpha_{\mathrm{Fe}}+\alpha_{\text {sand }}+\alpha_{\text {pumice }}+\alpha_{\mathrm{MnO} 2}\right) \\
& \mathrm{V}_{\mathrm{rz}}=\alpha_{\text {pore }} * \mathrm{~V}_{\mathrm{rz}}+\alpha_{\mathrm{Fe}} * \mathrm{~V}_{\mathrm{rz}}+\alpha_{\text {sand }} * \mathrm{~V}_{\mathrm{rz}}+\alpha_{\text {pumice }} * \mathrm{~V}_{\mathrm{rz}}+\alpha_{\mathrm{MnO} 2} * \mathrm{~V}_{\mathrm{rz}}
\end{aligned}
$$




$$
\mathrm{V}_{\mathrm{rz}}=\mathrm{V}_{\text {pore }}+\mathrm{V}_{\mathrm{Fe}}+\mathrm{V}_{\text {sand }}+\mathrm{V}_{\text {pumice }}+\mathrm{V}_{\mathrm{MnO} 2}
$$

153 Assuming $\mathrm{V}_{\mathrm{rz}}=1000 \mathrm{~mL}, \alpha_{\mathrm{Fe}}=0.192\left(\mathrm{P}_{\mathrm{Fe}}=30 \%\right), \alpha_{\text {sand }}=0.256\left(\mathrm{P}_{\text {sand }}=40 \%\right)$, $\alpha_{\text {pumice }}=$

$1540.128\left(\mathrm{P}_{\text {pumice }}=20 \%\right)$, and $\alpha_{\mathrm{MnO} 2}=0.064\left(\mathrm{P}_{\mathrm{MnO} 2}=10 \%\right)$, the volume of the materials are

155 192, 256, 128 and $64 \mathrm{~mL}$ respectively and $\mathrm{V}_{\text {pore }}=360 \mathrm{~mL}$.

156 Using Eq. $5\left(\mathrm{~m}_{\mathrm{i}}=\rho_{\mathrm{i}} * \mathrm{~V}_{\mathrm{i}}\right)$, the needed mass of each material can be calculated. Results showed 157 that $1498 \mathrm{~g}$ of $\mathrm{Fe}, 678 \mathrm{~g}$ of sand, $82 \mathrm{~g}$ of pumice and $224 \mathrm{~g}$ of $\mathrm{MnO}_{2}$ will be used and 158 homogeneously mixed to design the desired column.

159 The initial porosity of the resulted column is given by Eq. 11

$$
\Phi_{0}=(1-\mathrm{C})+\alpha_{\mathrm{Fe}} \phi_{\mathrm{Fe}}+\alpha_{\text {sand }} \phi_{\text {sand }}+\alpha_{\text {pumice }} \phi_{\text {pumice }}+\alpha_{\mathrm{MnO} 2} \phi_{\mathrm{MnO} 2}
$$

161 But Fe and sand (quartz) are non-porous, therefore $\Phi_{0}$ is given by:

$$
\Phi_{0}=(1-\mathrm{C})+\alpha_{\text {pumice }} \phi_{\text {pumice }}+\alpha_{\mathrm{MnO} 2} \phi_{\mathrm{MnO} 2}
$$

163 Using values above ( $\alpha_{\text {pumice }}=0.128$ and $\left.\alpha_{\mathrm{MnO} 2}=0.064\right), \phi=0.80(80 \%)$ for pumice, and $\phi=$ 0.25 (25\%) for $\mathrm{MnO}_{2}$, give an initial porosity of 0.48 (vs. 0.36 in a pure $\mathrm{Fe}^{0}$ column). This example shows an increase of the initial porosity by $33 \%$ for the given mixture.

\subsection{Working with a constant $\mathrm{Fe}^{0}$ mass}

167 To work with a constant $\mathrm{Fe}^{0}$ mass, the volume $\left(\mathrm{V}_{\mathrm{Fe}}\right)$ occupied by the given $\mathrm{Fe}$ mass is

168 calculated using Eq. 5. This volume represents a certain fraction of solid in the filter $\left(\alpha_{\mathrm{Fe}}\right.$ in

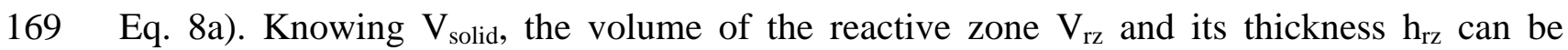
170 deduced using Eq. 3c and Eq. 6.

171 It is obvious, that $\mathrm{h}_{\mathrm{rz}}$ depends on the inner diameter of the filter. Accordingly, the simplest 172 way to investigate the effect of bed thickness on the efficiency of $\mathrm{Fe}^{0}$ beds is to work with a 173 constant $\mathrm{Fe}^{0}$ mass, representing a fix volumetric percentage of solid and using columns of 174 various internal diameters $\left(\mathrm{D}_{\mathrm{i}}\right)$.

175 Working with a constant $\mathrm{Fe}^{0}$ mass can be regarded as the most powerful tool to achieve 176 comparable results. For example, laboratory column experiments could be routinely 
177 performed with $100 \mathrm{~g}$ of $\mathrm{Fe}^{0}$ representing 30 vol-\% of the solid in the reactive zone.

178 Calculations show that the reactive zone will occupy a volume of $20 \mathrm{~mL}$. To have such a

179 volume using columns with inner diameters $\mathrm{D}_{1}(2.0 \mathrm{~cm}), \mathrm{D}_{2}(2.6 \mathrm{~cm})$ and $\mathrm{D}_{3}(5.0 \mathrm{~cm})$, the

180 column length should be 6.37, 3.77, and $1.02 \mathrm{~cm}$ respectively. All columns of Tab. 1 satisfy

181 this basic condition. However building an homogeneous $1.02 \mathrm{~cm}$ layer of " $\mathrm{Fe}$ " additive"

182 could be a difficult task. While repeating the calculations above with $250 \mathrm{~g} \mathrm{Fe}^{0}$ results show

183 that needed column lengths are $15.93,9.43$, and $2.55 \mathrm{~cm}$ respectively. While column $1(\mathrm{D}=2$

$184 \mathrm{~cm}, \mathrm{~L}=12 \mathrm{~cm})$ is no more applicable, filling column $3(\mathrm{D}=5 \mathrm{~cm})$ with only $2.55 \mathrm{~cm}$ of

185 homogeneous mixture could still be difficult to achieved. Therefore and objective could be a

186 minimum reactive zone length of $5 \mathrm{~cm}$. To achieve this thickness, a $\mathrm{Fe}^{0}$ of $500 \mathrm{~g}$ is needed for

187 column 3. This is necessarily coupled with longer experimental duration. As a result, it is 188 suggested that columns with more than $3 \mathrm{~cm}$ internal diameter are not suitable for short term 189 laboratory experiments. This suggestion is coupled with the desire to save $\mathrm{Fe}^{0}$ costs in 190 columns and to shorten experimental durations.

\section{$191 \quad 4.3 \quad$ Working with a constant initial porosity}

192 For column experiments performed with a constant $\mathrm{Fe}^{0}$ mass (e.g. 100 g), using various 193 additives could enable a constant initial porosity $\left(\Phi_{0}\right)$. The aim could be for example to 194 experimentally quantify the impact of $\mathrm{MnO}_{2}$ on $\mathrm{Fe}^{0}$ bed's hydraulic permeability. The length 195 of the reactive zone will vary as a function of the porosity of the tested additive. Eq. $11\left(\Phi_{0}=\right.$ $\left.196(1-C)+\Sigma \alpha_{i} \phi_{i}\right)$ should be solved while fixing one or two variables.

197 For example, the reference system uses $\mathrm{Fe}^{0}$ (100 g representing 50 vol-\%) and a limestone 198 with $\phi_{\text {lime }}=25 \%$. A second system having the same initial porosity $\left(\Phi_{0}\right)$ and been made up of 199 Fe $\left(\phi_{\mathrm{Fe}}=0 \%\right)$, quartz ( $\left.\phi_{\text {quartz }}=0 \%\right)$ and pumice should be designed. Which pumice amount 200 should be used? 
201 For the reference system, $\alpha_{\mathrm{Fe}}=0.32 ; \phi_{\mathrm{Fe}}=0 ; \alpha_{\text {lime }}=0.32$; and $\phi_{\text {lime }}=0.25$. Calculations give $202 \Phi_{0}=1-\mathrm{C}+0.32 * 0.25=0.44$. Now, Eq. $11\left(\Phi_{0}=0.44\right)$ should be written for the unknown 203 system and solved for $\phi_{\text {pumice}}$, given $\alpha_{\mathrm{Fe}}=0.32$ (or $\left.\alpha_{\text {quartz }}+\alpha_{\text {pumice }}=0.32\right)$. That is, with $\phi_{\mathrm{Fe}}=$ $204 \phi_{\text {quartz }}=0$ :

$$
\Phi_{0}=0.44=1-\mathrm{C}+\alpha_{\mathrm{Fe}} \phi_{\mathrm{Fe}}+\alpha_{\text {quartz }} \phi_{\text {quartz }}+\alpha_{\text {pumice }} \phi_{\text {pumice }}
$$

$$
\alpha_{\text {pumice }}=0.08 / \phi_{\text {pumice }}
$$

The pumices to be used are materials for which Eq. $11 \mathrm{~b}$ and the fundamental conditions $\alpha_{\text {quartz }}$

$208+\alpha_{\text {pumice }}=0.32$ and $\phi_{\text {pumice }}<0.9$ are respected. There are certainly a large number of possible 209 solutions but the appropriate solution will be dictated by pumice's availability. Table 3 210 summarizes 5 appropriate solutions corresponding to $\phi_{\text {pumice }}$ values varying from 0.33 to 0.80 .

211 Having the $\alpha_{\text {pumice }}$ (and $\alpha_{\text {quartz }}$ ) the volumes and the masses can be derived and used as 212 described above.

\section{Concluding remarks}

214 To date, the equivocal results published on contaminant removal in $\mathrm{Fe}^{0} / \mathrm{H}_{2} \mathrm{O}$ systems 215 demonstrate that the physico-chemical mechanisms of the remediation process still remain 216 unclear [38]. Available data were produced and interpreted based on the concept that $\mathrm{Fe}^{0}$ is a 217 reducing agent [1-4]. On the other side, available data are characterized by the diversity of 218 experimental conditions under which they are obtained (Tab. 1). This situation is not 219 favourable for reliable data comparison. In particular, further laboratory column studies 220 aiming at optimising field $\mathrm{Fe}^{0}$ bed design efforts should be acquired under reproducible 221 experimental conditions.

222 The present theoretical study has initiated a new path to an harmonized experimental protocol 223 for column experiments. It is proposed that $100 \mathrm{~g}$ or $250 \mathrm{~g}$ of $\mathrm{Fe}^{0}$ is used in a volumetric 224 proportion not larger than $50 \%$. The equations for material mixtures are established. It is hoped that researchers will use the developed tools to avoid inconsistent results which are 
most likely the product of inaccurate experimental designs. For example, while bed clogging

227 has been reported as the major drawback of the $\mathrm{Fe}^{0}$ technology, most researchers have used experimental designs favouring column clogging ( $\mathrm{Fe}^{0}>60$ vol-\%) [32].

229 Once the mass of $\mathrm{Fe}^{0}$ and its volumetric proportion are fixed several other factors can be 230 purposefully discussed. For example, the impact of: (i) the $\mathrm{Fe}^{0}$ average particle size, (ii) the 231 solution $\mathrm{pH}$, (iii) the water composition, (iv) water flow velocity. In all the case the 232 description of the experimental protocol should include and extensive description of used 233 materials (density, porosity, measured bed porosity). Finally, because clogging is the major 234 problem of $\mathrm{Fe}^{0}$ beds, expertise from other branches of environmental science dealing with 235 porous media clogging could be helpful for proper $\mathrm{Fe}^{0}$ bed design. In particular, much 236 impetus could come from the impact of bio-clogging on the evolution of the porosity of 237 constructed wetland [39-42].

\section{References}

239 [1] S.F. O’Hannesin, R.W. Gillham, Long-term performance of an in situ "iron wall" for remediation of VOCs, Ground Water 36 (1998) 164-170.

241 [2] A.D. Henderson, A.H. Demond, Long-term performance of zero-valent iron permeable reactive barriers: a critical review, Environ. Eng. Sci. 24 (2007) 401-423.

243 [3] A.B. Cundy, L. Hopkinson, R.L.D. Whitby, Use of iron-based technologies in contaminated land and groundwater remediation: A review, Sci. Tot. Environ. 400 (2008) 42-51.

[4] R. Thiruvenkatachari, S. Vigneswaran, R. Naidu, Permeable reactive barrier for groundwater remediation, J. Ind. Eng. Chem. 14 (2008) 145-156.

[5] A. Ghauch, H.A. Assi, A. Tuqan, Investigating the mechanism of clofibric acid removal in $\mathrm{Fe}^{0} / \mathrm{H}_{2} \mathrm{O}$ systems, J. Hazard. Mater. 176 (2010) 48-55.

[6] A. Ghauch, H.A. Assi, S. Bdeir, Aqueous removal of diclofenac by plated elemental iron: Bimetallic systems, J. Hazard. Mater. 182 (2010) 64-74. 
252 [7] C. Noubactep, A. Schöner, P. Woafo, Metallic iron filters for universal access to safe drinking water, Clean: Soil, Air, Water 37 (2009) 930-937.

254

255

256

257

258

259

260

261

262

263

264

265

266

267

268

269

270

271

272

[8] M.I. Litter, M.E. Morgada, J. Bundschuh, Possible treatments for arsenic removal in Latin American waters for human consumption, Environ. Pollut. 158 (2010) 1105-1118.

[9] C. Noubactep, S. Caré, Enhancing sustainability of household water filters by mixing metallic iron with porous materials, Chem. Eng. J. 162 (2010) 635-642.

[10] C. Noubactep, S. Caré, Dimensioning metallic iron beds for efficient contaminant removal, Chem. Eng. J. 163 (2010) 454-460

[11] A.M. Gottinger, D.J. Wild, D. McMartin, B. Moldovan,. D. Wang, Development of an iron-amended biofilter for removal of arsenic from rural Canadian prairie potable water, In: Water Pollution X. A.M. Marinov and C.A. Brebbia, Eds.; WIT Press: Ashurst, Southampton (2010) 333-344.

[12] C. Noubactep, A. Schöner, Metallic iron: dawn of a new era of drinking water treatment research? Fresen. Environ. Bull. 19 (2010) 1661-1668.

[13] C. Noubactep, Metallic iron for safe drinking water worldwide, Chem. Eng. J. 165 (2010) 740-749

[14] C. Noubactep, Processes of contaminant removal in " $\mathrm{Fe}^{0}-\mathrm{H}_{2} \mathrm{O}$ " systems revisited. The importance of co-precipitation, Open Environ. J. 1 (2007) 9-13.

[15] C. Noubactep, A critical review on the mechanism of contaminant removal in $\mathrm{Fe}^{0}-\mathrm{H}_{2} \mathrm{O}$ systems, Environ. Technol. 29 (2008) 909-920.

[16] C. Noubactep, An analysis of the evolution of reactive species in $\mathrm{Fe}^{0} / \mathrm{H}_{2} \mathrm{O}$ systems, J. Hazard. Mater. 168 (2009) 1626-1631.

[17] C. Noubactep, Elemental metals for environmental remediation: Learning from cementation process, J. Hazard. Mater. 181 (2010) 1170-1174.

[18] C. Noubactep, The fundamental mechanism of aqueous contaminant removal by metallic iron, Water SA 36 (2010) 663-670. 
[19] C. Noubactep, The suitability of metallic iron for environmental remediation, Environ. Progr. Sust. En. 29 (2010) 286-291.

[20] J.O. Peterson, G.F. Lee, Sorption capacity estimation for activated carbon packed columns, Water Res. 5 (1971) 717-721.

[21] C. Su, R.W. Puls, In situ remediation of arsenic in simulated groundwater using zerovalent iron: Laboratory column tests on combined effects of phosphate and silicate, Environ. Sci. Technol. 37 (2003) 2582-2587.

[22] S. Kundu, A.K. Gupta, Analysis and modeling of fixed bed column operations on As(V) removal by adsorption onto iron oxide-coated cement (IOCC), J. Colloid Interf. Sci. 290 (2005) 52-60.

[23] K.L. McGeough, R.M. Kalin, P. Myles, Carbon disulfide removal by zero valent iron, Environ. Sci. Technol. 41 (2007) 4607-4612.

[24] T.-H. Wang, M.-H. Li, S.-P. Teng, Bridging the gap between batch and column experiments: A case study of Cs adsorption on granite, J. Hazard. Mater. 161 (2009) 409-415.

[25] C. Noubactep, A.-M.F. Kurth, M. Sauter, Evaluation of the effects of shaking intensity on the process of methylene blue discoloration by metallic iron, J. Hazard. Mater. 169 (2009) 1005-1011.

[26] C. Noubactep, T. Licha, T.B. Scott, M. Fall, M. Sauter, Exploring the influence of operational parameters on the reactivity of elemental iron materials, J. Hazard. Mater. 172 (2009) 943-951.

[27] M. Gheju, I. Balcu, Hexavalent chromium reduction with scrap iron in continuous-flow system. Part 2: Effect of scrap iron shape and size, J. Hazard. Mater. 182 (2010) 484493.

[28] C. Noubactep, Characterizing the reactivity of metallic iron in $\mathrm{Fe}^{0} / \mathrm{EDTA} / \mathrm{H}_{2} \mathrm{O}$ systems with column experiments, Chem. Eng. J. 162 (2010) 656-661. 
[29] A. Luna-Velasco, R. Sierra-Alvarez, B. Castro, J.A. Field, Removal of nitrate and hexavalent uranium from groundwater by sequential treatment in bioreactors packed with elemental sulfur and zero-valent iron, Biotechnol. Bioeng. 107 (2010) 933-942.

[30] P. Westerhoff, J. James, Nitrate removal in zero-valent iron packed columns, Wat. Res. 37 (2003) 1818-1830.

[31] N. Moraci, P.S. Calabrò, Heavy metals removal and hydraulic performance in zerovalent iron/pumice permeable reactive barriers, J. Environ. Manag. 91 (2010) 23362341.

[32] C. Noubactep, S. Caré, F. Togue-Kamga, A. Schöner, P. Woafo, Extending service life of household water filters by mixing metallic iron with sand, Clean - Soil, Air, Water 38

[33] Y.B.G. Varma, T. Gopichand, D. Venkateswarlu, Particle size distribution in compacts of solids, J. Chem. Eng. Data 13 (1968) 498-503.

[34] A. Felinger, G. Guiochon, Optimization of the experimental conditions and the column design parameters in displacement chromatography, J. Chromatography A609 (1992) 35-47.

[35] S.I.F. Badawy, M.A. Hussain, Effect of starting material particle size on its agglomeration behavior in high shear wet granulation, AAPS Pharm. Sci. Tech. 5

[36] R.S. Maier, Kroll D.M., R.S. Bernard, S.E. Howington, J.F. Peters, H.T. Davis, Enhanced dispersion in cylindrical packed beds, Phil. Trans. R. Soc. Lond. A 360 (2002) 497-506.

[37] R.S. Maier, D.M. Kroll, H.T. Davis, Diameter-dependent dispersion in packed cylinders, AIChE Journal 53 (2007), 527-530. 
[38] S. Comba, A. Di Molfetta, R. Sethi, A comparison between field applications of nano-, micro-, and millimetric zero-valent iron for the remediation of contaminated aquifers, Water Air Soil Pollut. 215 (2011) 595-607.

[39] M. Thullner, Comparison of bioclogging effects in saturated porous media within oneand two-dimensional flow systems, Ecol. Eng. 36 (2010) 176-196.

[40] A. Wanko, G. Tapia, R. Mosé, C. Gregoire, A new empirical law to accurately predict solute retention capacity within horizontal flow constructed wetlands, Ecol. Eng. 37 (2011) 636-643.

[41] D. Yuan, L. Zhang, B. Xi, L. He, C. Yan, H. Liu, Design and performance of a filtrationadsorption pool train and drawing water system for small urban recreational water pollution control, Ecol. Eng. 37 (2011) 648-653.

[42] A. Brovelli, O. Carranza-Diaz, L. Rossi, D.A. Barry, Design methodology accounting for the effects of porous medium heterogeneity on hydraulic residence time and biodegradation in horizontal subsurface flow constructed wetlands, Ecol. Eng. (2010), doi:10.1016/j.ecoleng.2010.04.031. 
344 Table 1: Variability of the operational conditions for column experiments as illustrated by 345 material masses likely to be used in six different columns. D is the internal diameter of the 346 column and L its length. It is assumed that the entire column volume is filled by spherical 347 particle of $\mathrm{Fe}^{0}$, sand or pumice in an ideal cubic packing $(\mathrm{C}=0.64)$.

348

\begin{tabular}{cccccccc}
\hline $\mathbf{D}$ & $\mathbf{L}$ & $\mathbf{V}_{\text {column }}$ & $\mathbf{V}_{\text {solid }}$ & $\mathbf{m}_{\text {Fe }}$ & $\mathbf{m}_{\text {sand }}$ & $\mathbf{m}_{\text {pumice }}$ & Ref. \\
$(\mathrm{cm})$ & $(\mathrm{cm})$ & $\left(\mathrm{cm}^{3}\right)$ & $\left(\mathrm{cm}^{3}\right)$ & $(\mathrm{kg})$ & $(\mathrm{kg})$ & $(\mathrm{kg})$ & \\
\hline 2.0 & 12 & 37.7 & 24.1 & 0.19 & 0.06 & 0.015 & {$[27]$} \\
\hline 2.6 & 40 & 212.5 & 136.0 & 1.06 & 0.34 & 0.087 & {$[28]$} \\
\hline 4.1 & 25 & 330.0 & 211.0 & 1.60 & 0.60 & 0.135 & {$[29]$} \\
\hline 5.0 & 30 & 589.3 & 377.1 & 2.94 & 0.94 & 0.241 & {$[30]$} \\
\hline 5.0 & 50 & 982.1 & 628.6 & 4.90 & 1.57 & 0.402 & {$[31]$} \\
\hline 5.0 & 100 & 1964.3 & 1257.1 & 9.81 & 3.14 & 0.805 & {$[32]$} \\
\hline
\end{tabular}


351 Table 2: Relation between the volumetric fraction $\left(\alpha_{i}\right)$ of solid materials in the column $\left(\alpha_{\text {pore }}\right.$ $352=0.36)$ and their volumetric percent $\left(\mathrm{P}_{\mathrm{i}}\right)$ as solid. $\alpha_{\mathrm{i}}$ is obtained by a rule of proportion 353 relative to ( $\alpha_{\max }=0.64$ corresponding to $100 \%$ solid). $\alpha$ values are very useful for multi-solid 354 system designs (see text).

\begin{tabular}{cccccccccccc}
\hline $\mathbf{P}_{\mathbf{i}}$ & 0 & 10 & 20 & 30 & 40 & 50 & 60 & 70 & 80 & 90 & 100 \\
\hline $\boldsymbol{\alpha}_{\mathbf{i}}$ & 0.00 & 0.064 & 0.128 & 0.192 & 0.256 & 0.320 & 0.384 & 0.448 & 0.512 & 0.576 & 0.640
\end{tabular}

355

356 
356 Table 3: selected appropriate solutions for Eq. 11b.

357

\begin{tabular}{cccccc}
\hline$\alpha_{\text {quartz }}$ & 0.08 & 0.13 & 0.16 & 0.19 & 0.22 \\
\hline$\alpha_{\text {pumice }}$ & 0.24 & 0.19 & 0.16 & 0.13 & 0.1 \\
\hline$\phi_{\text {pumice }}$ & 0.33 & 0.42 & 0.50 & 0.62 & 0.80
\end{tabular}

358

359 
360 Figure 1: Evolution of the material weight percent in a ternary system $\mathrm{Fe}^{0} / \mathrm{sand} /$ pumice as the 361 initial 50:50 sand:pumice mixture (vol) is progressively amended with $\mathrm{Fe}^{0}$. The sand:pumice 362 volumetric ratio is kept constant during the whole simulation. It is evident that due to 363 difference in densities the weight percent variation is different for individual materials.

364

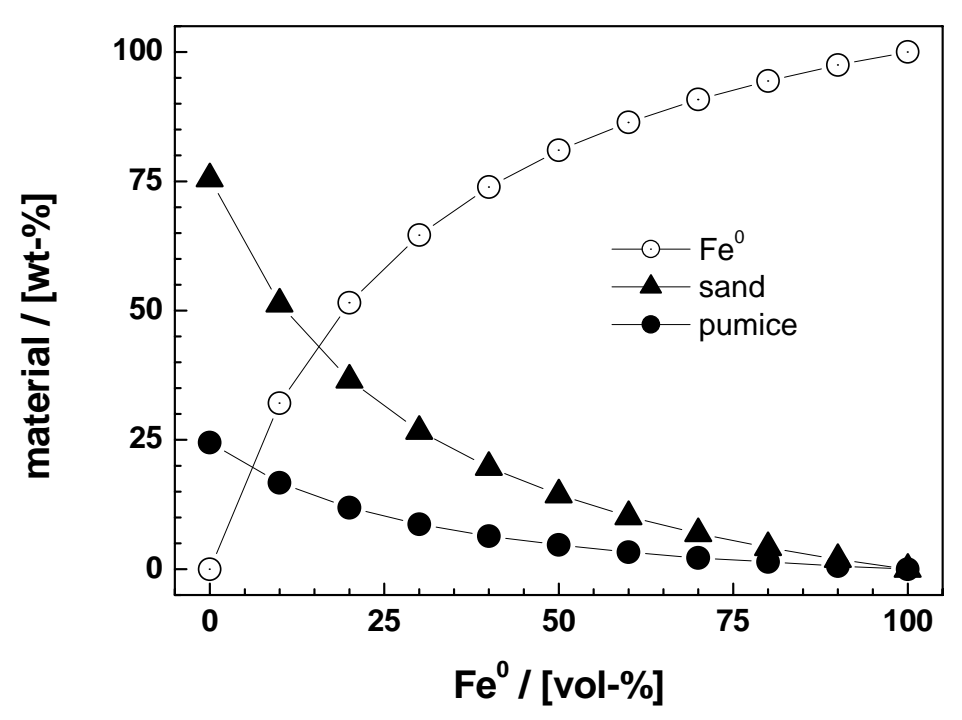

365

366 